\title{
Application of gonadotropin releasing hormone in hypogonadotropic hypogonadism - diagnostic and therapeutic aspects
}

\author{
Henriette A Delemarre-van de Waal \\ Department of Pediatrics, Institute of Clinical and Experimental Neurosciences, VU University Medical Center, Amsterdam, The Netherlands \\ (Correspondence should be addressed to H A Delemarre-van de Waal; Email: H.Delemarre@vumc.nl)
}

\begin{abstract}
Background: Puberty is the result of reactivation of the gonadotropin releasing hormone (GnRH) pulse generator resulting in an increasing release of GnRH by the hypothalamus, which stimulates the gonadotropic cells of the pituitary to synthesize and secrete LH and FSH. Hypogonadotropic hypogonadism $(\mathrm{HH})$ is often the result of GnRH deficiency. The clinical picture is characterized by the absence of pubertal development and infertility. It is difficult to differentiate HH from delayed puberty since low gonadotropin and low testosterone levels are found in both conditions. We hypothesized that long-term GnRH administration may differentiate between the two conditions by a difference in the increase of gonadotropins, the idea being that in normal delayed puberty the pituitary of the patient has been primed with GnRH during the fetal and early postnatal period.

Patients: Seventeen adolescents suspected of having hypogonadotropic hypogonadisn were treated with pulsatile GnRH for 7 days. At the present time, the diagnosis of these patients is known and the results of the long-term GnRH stimulation have been evaluated according to the present diagnosis.

Results: The results show that the increase in gonadotropins following GnRH treatment is similar in both conditions. Therefore, at a prepubertal age a normal delayed puberty cannot be distinguished from hypogonadotropic hypogonadism using long-term $\mathrm{GnRH}$ stimulation. Long-term pulsatile GnRH treatment is a physiological therapy for the induction of puberty. Unlike testosterone it has the advantage of stimulation of testicular growth and fertility, as well as virilization, in males.

We have treated 68 male patients with $\mathrm{HH}$ with pulsatile GnRH. The results show testicular growth and virilization in all the patients and spermatogenesis in 58 patients. Wearing a portable pump is cumbersome. However, the patients were very motivated and adapted very easily to this inconvenience. When spermatogenesis had developed, GnRH treatment was changed to human chorionic gonadotropin (hCG) administration 1-2 times per week intramuscularly or subcutaneously. During hCG therapy spermatogenesis was maintained or even improved. At least ten patients fathered children.

Conclusion: Pulsatile GnRH cannot distinguish between a normal delayed puberty and a hypothalamic defect in still prepubertal patients. Pulsatile GnRH offers an appropriate way to initiate testicular growth including virilization and fertility in males with hypogonadotropic hypogonadism.
\end{abstract}

European Journal of Endocrinology 151 U89-U94

\section{Introduction}

Puberty is the result of increasing gonadotropin releasing hormone $(\mathrm{GnRH})$ release by the hypothalamus followed by a complex sequence of endocrine changes with functioning of negative and positive feedbacks, and associated with the development of sex characteristics, a growth spurt and reproductive competence.

Dierschke and co-workers (1) were the first to observe a pulsatile secretion pattern of luteinizing hormone (LH) in primates. In the human the gonadotropic axis is already active in the fetal period. At mid-gestation, at completion of the vascular portal system, gonadotropin levels reach very high values (2). This peak is followed by a decrease, presumably the result of a negative feedback to sex steroids in combination with central inhibiting influences on GnRH release. During the transient increase in gonadotropins after birth, LH levels already show a pulsatile pattern (3).

In adolescence the first endocrine change is the occurrence of an LH increase during the night only (4). LH and follicle stimulating hormone (FSH) then increase during the day and the night until adult levels have been achieved. The day-night rhythm is characteristic for pubertal maturation and disappears in the adult endocrine state. LH secretion changes 
through an increase in both LH pulse frequency and pulse amplitude, which is assumed to reflect the nature of GnRH stimulation (5).

If an adolescent remains in the prepubertal state, it is difficult to differentiate between delayed puberty and hypogonadotropic hypogonadism, since both conditions are characterized by hypothalamic inactivity. The diagnosis can be suspected, however, on clinical grounds. Delayed puberty is often familial and associated with short stature. At the delay, height velocity will slow down further and bone maturation will be delayed. In general, hypogonadotropic hypogonadism patients have a normal height. There is no clear dip in height velocity when puberty does not appear, but height velocity will maintain its prepubertal pace. Bone maturation continues slowly.

The GnRH test is not a reliable test to differentiation between the two states. In the normal prepubertal state and in the hypogonadotropic state there is hardly any increase in the gonadotropins response to GnRH. In fact, the response to a GnRH test reflects the priming effect of GnRH stimulation beforehand which is absent or low in both conditions. If the patient is at a pubertal age but still without any clinical signs of puberty, a 24-hour pattern of LH may provide evidence for a delayed puberty. This pattern is then characterized by a night time increase in LH or a slightly increased FSH level during the day $(4,6)$. This paper will discuss the possibilities of long-term pulsatile stimulation with native $\mathrm{GnRH}$ in order to differentiate between normal prepubertal and hypogonadotropic states as well as its use for therapeutic options in adolescents.

\section{Patients and methods}

The group of patients consisted of adolescents in whom the diagnosis of hypogonadotropic hypogonadism was suspected. If there was an additional endocrine deficiency, adequate substitution was given.

\section{Diagnostic GnRH administration}

We hypothesized that in the case of hypogonadotropic hypogonadism there had been no or decreased priming of the pituitary leading to a diminished or delayed LH and FSH response to exogenous GnRH stimulation.

Seventeen adolescents suspected of having hypogonadotropic hypogonadism were treated with $\mathrm{GnRH}$ for 7 days. On days 1 and 7 a standard GnRH test was performed. GnRH was administered in a pulsatile fashion in a dose of $20 \mu \mathrm{g} / 1.73 \mathrm{~m}^{2}$ per pulse every $90 \mathrm{~min}$ intravenously. On days 2 through 6, blood was collected for $\mathrm{LH}$ and FSH determination every morning just prior to the GnRH administration at 0900 h. Gonadal function was evaluated by measuring plasma estradiol levels in girls and testosterone levels in boys on days 1 and 7 .

At the present time, we know the correct diagnosis of these 17 patients since we followed-up those who were hypogonadotropic and those who entered puberty spontaneously.

\section{Therapeutic use of GnRH}

The group of patients consisted of 68 males with hypogonadotropic hypogonadism with a mean age of 20.4 years (range 14.3-42 years). Twenty-four of them were pretreated with androgens for more than 3 months (long term), 11 had received gonadotropins to induce testicular growth but without success. Twenty patients underwent surgical correction of cryptorchidism, 14 on both testes, two on the left testis, four on the right testis.

Twenty-eight of them suffered from idiopathic hypogonadotropic hypogonadism (IHH), 23 from Kallmann syndrome (KS), hypogonadotropic hypogonadism in combination with anosmia, nine from multiple pituitary hormone deficiencies (MPHD), and eight from a brain tumor which had been surgically removed.

Before GnRH therapy, gonadotropin secretion was evaluated by 7-day GnRH administration (7). If, based on the results, pituitary function was assumed to be intact with respect to gonadotropin secretion, then GnRH treatment was applied.

Treatment with GnRH consisted of GnRH infusion (Lutrelef, Ferring GmbH, Kiel, Germany) in a pulsatile fashion using a portable pump (Zyklomat, Ferring $\mathrm{GmbH})$. The first 14 patients had been treated with a pulse dose of $20 \mu \mathrm{g}$ every $90 \mathrm{~min}$. Since we observed relatively high levels of gonadotropins and testosterone levels, we decreased the dose in the following patients. Sixteen patients started with $10 \mu \mathrm{g}$ pulses; in three of them the dose needed to be increased. Another eight patients had been treated with $5 \mu \mathrm{g}$ pulses, in one the dose needed to be increased. Thirty patients started with $2 \mu \mathrm{g}$ pulses; in six the dose had to be increased. Forty-five patients were treated with GnRH intravenously, the other 23 with subcutaneous infusion.

The results of the treatment were followed by regular physical examination with special attention to testicular volume, as well as measurements of gonadotropins and testosterone levels. If needed, the GnRH dose was adjusted. Spermatogenesis was evaluated by semen analysis or investigation of a morning urine sample for spermatozoa.

The final goal of treatment was the achievement of spermatogenesis. When a patient achieved a normal testicular volume but remained azoospermic, treatment was discontinued. Subsequently, the patients were treated with human chorionic gonadotropin (hCG) 1500-3000 units one to two times a week intramuscularly and subcutaneously.

Statistical analysis was performed using non-parametric tests. A significant difference was considered when $P$ was equal to or below 0.05 . 
The diagnostic and therapeutic studies were performed with the permission of the subcommittee for research on human subjects of the VU University Medical Center.

\section{Results}

\section{Diagnostic GnRH administration}

All 17 patients except one showed an increase in LH, FSH and estradiol or testosterone levels during the seven days of GnRH administration. Figure 1a exemplifies the pattern of LH and FSH in a 14.7-year-old male adolescent without any sex characteristics. Figure $1 \mathrm{~b}$ shows the curve of a 15-year-old girl in prepubertal stage B1,P1, known to have pituitary hypoplasia.

Seven out of the 17 patients suspected of having hypogonadotropic hypogonadism appeared to have a $\mathrm{GnRH}$ deficiency. They never entered puberty spontaneously, in contrast to the other ten patients. Figure 2 shows the increase in LH levels of the two groups (delayed puberty and GnRH deficiency) during the seven days of pulsatile GnRH stimulation. LH and FSH showed similar patterns. In both groups gonadotropins increased during the GnRH stimulation. There were no differences in the increase between the two groups. The individual levels overlapped on all days.

\section{Therapeutic use of native GnRH}

During treatment with GnRH, LH, FSH and testosterone levels increased in all patients. In 56 out of the

(a)
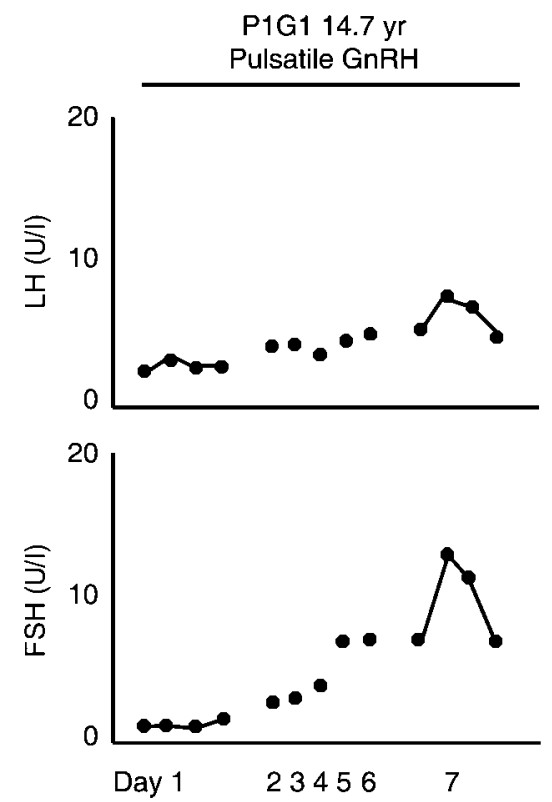

68 patients testosterone levels achieved adult levels defined as a total testosterone level above $10 \mathrm{nmol} / \mathrm{l}$. The other ten patients showed testosterone levels between 6.3 and $9.0 \mathrm{nmol} / \mathrm{l}$.

With respect to the sex characteristics, testicular growth and virilization occurred in all patients. At the start of $\mathrm{GnRH}$ treatment mean testicular volumes were $4.2,2.6,3.5$ and $4.3 \mathrm{ml}$ in patients with IHH, KS, MPHD and after removal of a brain tumor respectively (Table 1). Testicular volume before treatment was significantly less in the patients with KS. Mean testicular volume increased to 14.2 , 10.6, 11.6 and $18.2 \mathrm{ml}$ respectively; testicular volumes at the end of treatment were significantly higher in the brain tumor patients.

Spermatogenesis was examined in 60 patients at the end of GnRH treatment (Table 2). Spermatozoa were present in 51, while nine showed azoospermia. This investigation was not performed in eight males. During follow-up after the GnRH treatment, another two patients developed spermatogenesis during hCG treatment, while five out of the eight patients in whom spermatogenesis had not been investigated, appeared to have sperm as well.

In summary, in 58 out of 68 patients spermatogenesis was induced. All 14 patients who underwent surgery on both testes because of cryptorchidism developed spermatogenesis under GnRH treatment or during the subsequent hCG treatment.

In eight patients previously treated long term with gonadotropins without success, GnRH treatment was able to induce spermatogenesis.

(b)
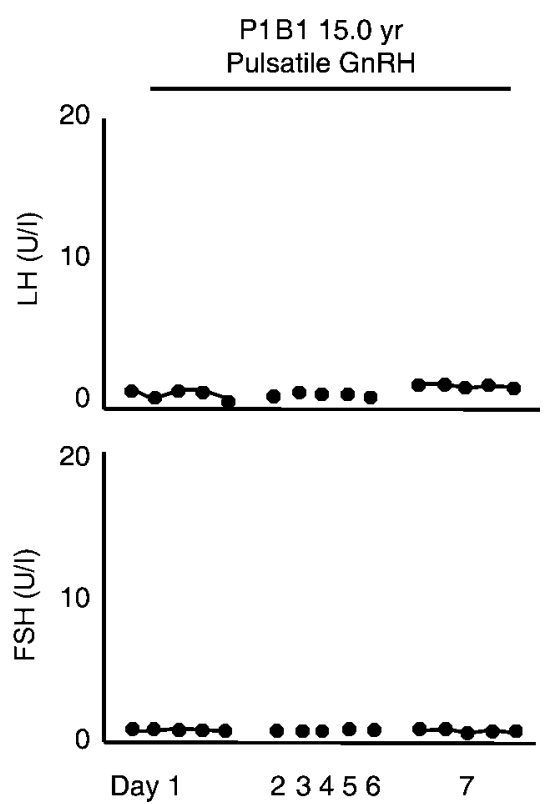

Figure $1 \mathrm{LH}$ and FSH levels during pulsatile i.v. administration of GnRH for 7 days (shown by the hoirizontal bar). On day 1 and day 7 the results of a standard GnRH test (100 $\mu$ g i.v.) are depicted. The results in a 14.7-year-old boy in prepubertal stage P1,G1 (a) and in a prepubertal $(\mathrm{P} 1, \mathrm{~B} 1)$ girl known to have multiple pituitary hormone deficiencies due to pituitary hypoplasia (b) are shown. 


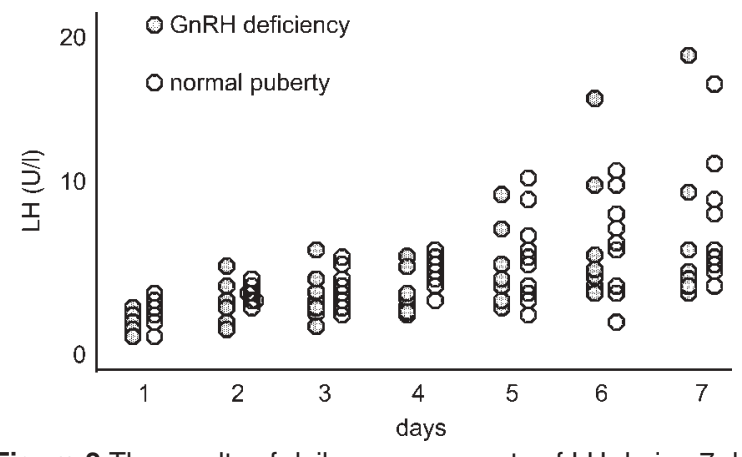

Figure 2 The results of daily measurements of LH during 7 days of $\mathrm{GnRH}$ treatment in 17 patients. After ten years it appeared that seven of the 17 patients had $\mathrm{GnRH}$ deficiency, while ten entered puberty spontaneously.

Table 1 Testicular volume (mean \pm S.D.) before and at discontinuation of $\mathrm{GnRH}$ treatment.

\begin{tabular}{lrcc}
\hline & & \multicolumn{2}{c}{ Testicular volume (ml) } \\
\cline { 3 - 4 } & $\boldsymbol{n}$ & Pre-treatment & Post-treatment \\
\hline $\mathrm{IHH}$ & 28 & $4.2 \pm 3.1(1-12)$ & $14.2 \pm 4.2(6-20)$ \\
KS & 23 & $2.6 \pm 1.3(1-4)^{\star}$ & $10.6 \pm 4.0(5-20)$ \\
MPHD & 9 & $3.5 \pm 2.6(1-8)$ & $11.6 \pm 3.8(8-20)$ \\
Brain tumor & 8 & $4.3 \pm 3.4(1-12)$ & $18.2 \pm 6.2(12-25)^{*}$ \\
\hline
\end{tabular}

* $P<0.05$ compared with the other groups at the same treatment stage. $\mathrm{IHH}$, idiopathic hypogonadotropic hypogonadism; KS, Kallmann syndrome; MPHD, multiple pituitary hormone deficiencies.

Table 2 Spermatogenesis at discontinuation of $\mathrm{GnRH}$ treatment.

\begin{tabular}{|c|c|c|c|c|}
\hline & \multirow[b]{2}{*}{$n$} & \multicolumn{2}{|c|}{ Spermatozoa } & \multirow[b]{2}{*}{ Not done } \\
\hline & & Present in semen/urine & Absent & \\
\hline $\mathrm{IHH}$ & 28 & 24 & 2 & 2 \\
\hline KS & 23 & 14 & 7 & 2 \\
\hline MPHD & 9 & 7 & - & 2 \\
\hline Brain tumor & 8 & 6 & - & 2 \\
\hline Total & 68 & 51 & $9(2+\mathrm{hCG})^{*}$ & $8(5+)^{\star *}$ \\
\hline
\end{tabular}

$\mathrm{IHH}$, idiopathic hypogonadotropic hypogonadism; KS, Kallmann syndrome; MPHD, multiple pituitary hormone deficiencies. ${ }^{*}$ Two of the nine patients developed sperm during hCG treatment; ${ }^{*}$ of the eight patients not evaluated on sperm, five appeared to have sperm.

\section{Follow-up}

After discontinuation of GnRH treatment, hCG treatment was initiated in a dose of 1500-3000 units intramuscularly twice per week. The dose was adjusted based on the testosterone levels. Experience with the treatment allowed the schedule to be changed to a less frequent (once a week) and subcutaneous way of administration controlled by adequate testosterone levels. During follow-up, spermatogenesis was maintained in most patients and was even improved in some patients.

As far as we know, ten of these men fathered children. In four male infants we measured gonadotropin and testosterone levels between the ages of 7 and 16 weeks. LH levels ranged between 1.1 and $3.6 \mathrm{U} / \mathrm{l}$,
FSH between 0.6 and $2.2 \mathrm{U} / \mathrm{l}$. All four boys had measurable testosterone levels between 1.6 and $7.2 \mathrm{nmol} / \mathrm{l}$.

\section{Problems}

During both subcutaneous and intravenous administration of pulsatile GnRH, desensitization may occur. A short treatment pause or increasing the $\mathrm{GnRH}$ pulse dose could restore gonadotropin secretion.

The intravenous catheters may cause phlebitis; a low dose of heparin $(100-300 \mathrm{U} / \mathrm{ml})$ as well as of prednisolone $(0.03-0.1 \mathrm{mg} / \mathrm{ml})$ may prevent these problems. In the case of subcutaneous treatment these additives were not needed.

During treatment hypogonadotropic adolescents underwent a progressive puberty, which many of them found difficult to adjust to mentally. In these cases, psychological counselling was offered.

\section{Discussion}

With regard to diagnostic aspects, GnRH was able to induce increasing gonadotropin secretion in all but one of the patients. One girl known to have hypogonadotropic hypoplasia and, as a consequence, multiple hormone deficiencies, appeared to suffer from hypogonadotropic hypogonadism as well. This was confirmed by a longer treatment with pulsatile $\mathrm{GnRH}$ administration (data not shown). This pattern of response indicates that, at least, we are able to distinguish a pituitary defect from a hypothalamic disorder. A pituitary defect also indicates that the patient cannot be treated for induction of ovulation or spermatogenesis by GnRH therapy.

The changing pattern in patients with a $\mathrm{GnRH}$ deficiency and delayed puberty shows that pulsatile $\mathrm{GnRH}$ is able to modify the pituitary response to GnRH within several days (8). Evidence for the idea that patients with a GnRH deficiency have a delayed response to $\mathrm{GnRH}$ compared with patients with delayed puberty as a result of impaired priming during the fetal and infant period was not found. There were no significant differences in LH, FSH and sex steroid levels between hypogonadotropic hypogonadism and delayed puberty. The patterns of the increasing levels of gonadotropins completely overlap throughout the seven days of GnRH stimulation. All patients were included in the follow-up. Twelve out of them achieved either short-term or long-term treatment to initiate puberty if spontaneous onset did not appear at an appropriate time. To confirm the diagnosis, treatment was discontinued after several years.

The GnRH agonist has been described to be an alternative to distinguish delayed puberty from hypogonadotropic hypogonadism (9). However, the paper by Kauschansky et al. (9) shows that both the native GnRH test and the GnRH agonist test elicit significantly higher levels of LH and FSH in boys with delayed puberty compared with hypogonadotropic boys (9). 
In fact, the basal FSH levels were already higher in delayed puberty, indicating that there is some GnRH stimulation (6). The boys with delayed puberty showed an increase in testicular volume over the following year.

Clinical findings such as testicular volume, growth pattern, and bone age in combination with a basal blood sampling family history, will give a probable diagnosis in most adolescents. When a probable diagnosis cannot be established, additional testing can provide information on the function of the hypothalamic-pituitary-gonadal axis.

With regard to the diagnostic procedure, we may conclude that pulsatile administration is capable of differentiating between a pituitary and a hypothalamic defect in the case of hypogonadotropic hypogonadism. In addition, a good response to pulsatile GnRH implies that the patient can be treated with pulsatile $\mathrm{GnRH}$ to induce puberty and fertility.

The therapeutic use of synthetic GnRH appeared to be an adequate way to treat female and male infertility problems. Presumably as a result of inadequate therapeutic schedules, the first results in males were very disappointing $(10,11)$. However, when GnRH was administered in a pulsatile fashion stimulation of testicular growth, including spermatogenensis, could be achieved $(12,13)$. The question arises as to whether gonadotropin therapy might achieve similar results as GnRH treatment. Schopohl and co-workers (14) reported on a comparison of both treatment regimens in males. They concluded that both GnRH and gonadotropins are able to induce testicular growth and steroidogenesis. Gonadotropin treatment resulted in higher testosterone and estradiol levels, presumably due to overstimulation. Consequently, the elevated estradiol levels caused gynecomastia, which was experienced as an inconvenient side effect. In their study, they observed higher testicular volumes in the GnRH-treated males. Furthermore, spermatogenesis developed in ten out of 16 investigated males treated with GnRH and in eight out of 17 males treated with gonadotropins,

In our study we observed a successful treatment in males who had had a previous failure on gonadotropin therapy. Therefore, it appears that, especially in the congenital form of hypogonadotropic hypogonadism, GnRH therapy is the most adequate and successful treatment to initiate testicular development. The difference between congenital and aquired hypogonadotropic hypogonadism may be the result of early life stimulation. During the fetal period as well as after birth, endogenous gonadotropins normally stimulate the testes. These short periods of stimulation may program or organize testicular function, which may be essential for later development (15).

Why the testes of congenital hypogonadotropic patients respond better to $\mathrm{GnRH}$ treatment than to exogenous gonadotropins is unknown. It may be due to overstimulation by gonadotropins and therefore induction of desensitization at the testicular level. During GnRH treatment a negative feedback of testicular products at the pituitary level develops that allows the testes to control their own gonadotropin stimulation, thereby preventing testicular overstimulation.

The high outcome of spermatogenesis achieved during GnRH treatment is remarkable. It was possible to induce spermatogenesis in patients with relatively small testes, well below adult size (above $20 \mathrm{ml}$ ) as well as in patients who underwent surgical correction of their bilateral cryptorchidism.

Once spermatogenesis has been achieved, hCG is able to maintain or even improve spermatogenesis. For continuation of spermatogenesis a high local testosterone level in the testis is needed.

The postnatal gonadotropin elevation during the first months of life offers us the opportunity to evaluate the hypothalamic-gonadal axis in the offspring of fathers with hypogonadotropic hypogonadism (15). This condition can be inherited as an X-linked, autosomal dominant or autosomal recessive mode. Mutations are described in the KAL-1 gene located on the X-chromosome and in the KAL-2 gene encoding for the fibroblastic growth factor receptor $1(16,17)$. Mutations are not always detected, also in families with a clear pattern of inheritance.

During the 3-month golden window after birth, increased levels of gonadotropins (higher than the low prepubertal levels) and testosterone indicate that the gonadal axis is intact and the diagnosis of $\mathrm{HH}$ can be excluded. It is not possible to test after the age of 6 months because gonadotropins will decrease to prepubertal levels at that time due to the intrinsic restraint that inhibits $\mathrm{GnRH}$ activity until puberty.

Wearing a portable pump to deliver pulstile $\mathrm{GnRH}$ can be cumbersome. However, nowadays many boys wear mobile phones and audio-players on their belts. Therefore, adolescents can adapt easily to this situation.

In conclusion, pulsatile GnRH application is a feasible way to induce virilization and testicular growth including spermatogenesis in males with hypogonadotropic hypogonadism. This method of treatment may be especially beneficial to those patients with a congenital form of this condition.

\section{References}

1 Dierschke DJ, Bhattacharya AN, Atkinson LE \& Knobil E. Circhoral oscillations of plasma LH levels in the ovariectomized rhesus monkey. Endocrinology 197087 850-853.

2 Kaplan SL \& Grumbach MM. The ontogenesis of human foetal hormones. II. Luteinizing hormone (LH) and follicle stimulating hormone (FSH). Acta Endocrinologica 197681 808-829.

3 Waldhauser F, Weissenbacher G, Frisch H \& Pollak A. Pulsatile secretion of gonadotropins in early infancy. European Journal of Pediatrics $198113771-74$

4 Wennink JM, Delemarre-van de Waal HA, van Kessel H, Mulder GH, Foster JP \& Schoemaker J. Luteinizing hormone 
secretion patterns in boys at the onset of puberty measured using a highly sensitive immunoradiometric assay. Journal of Clinical Endocrinology and Metabolism 198867 924-928.

5 Wennink JM, Delemarre-van de Waal HA, Schoemaker R, Schoemaker H \& Schoemaker J. Luteinizing hormone and follicle stimulating hormone secretion patterns in girls throughout puberty measured using highly sensitive immunoradiometric assays. Clinical Endocrinology 199033 333-344.

6 Odink RJ, Schoemaker J, Schoute E, Herdes E \& Delemarre-van de Waal HA. Predictive value of serum follicle-stimulating hormone levels in the differentiation between hypogonadotropic hypogonadism and constitutional delay of puberty. Hormone Research $199849279-287$.

7 Delemarre-van de Waal HA, Van den Brande JL \& Schoemaker J. Prolonged pulsatile administration of luteinizing hormone-releasing hormone in prepubertal children: diagnostic and physiologic aspects. Journal of Clinical Endocrinology and Metabolism 1985 $61859-867$.

8 Valk TW, Corley KP, Kelch RP \& Marshall JC. Hypogonadotropic hypogonadism: hormonal responses to low dose pulsatile administration of gonadotropin-releasing hormone. Journal of Clinical Endocrinology and Metabolism 198051 730-738.

9 Kauschansky A, Dickerman Z, Phillip M, Weintrob N \& Strich D. Use of GnRH agonist and human chorionic gonadotrophin tests for differentiating constitutional delayed puberty from gonadotrophin deficiency in boys. Clinical Endocrinology $2002 \mathbf{5 6}$ 603-607.

10 Krabbe S \& Skakkebaek NE. Gonadotropin-releasing hormone (LH-RH) and human chorionic gonadotropin in the treatment of two boys with hypogonadotrophic hypogonadism. Acta Paediatrica Scandinavica $197766361-365$.

11 Rabin D \& McNeil LW. Long term therapy with luteinizing hormone-releasing hormone in isolated gonadotropin deficiency: failure of therapeutic response. Journal of Clinical Endocrinology and Metabolism 198152 557-561.
12 Skarin G, Nillius SJ, Wibell L \& Wide L. Chronic pulsatile low dose GnRH therapy for induction of testosterone production and spermatogenesis in a man with secondary hypogonadotropic hypogonadism. Journal of Clinical Endocrinology and Metabolism $1982 \mathbf{5 5}$ 723-726.

13 Delemarre-van de Waal HA. Induction of testicular growth and spermatogenesis by pulsatile, intravenous administration of gonadotrophin-releasing hormone in patients with hypogonadotrophic hypogonadism. Clinical Endocrinology 199338 473-480.

14 Schopohl J, Mehltretter G, von Zumbusch R, Eversmann T \& von Werder K. Comparison of gonadotropin-releasing hormone and gonadotropin therapy in male patients with idiopathic hypothalamic hypogonadism. Fertility and Sterility 199156 1143-1150.

15 Evain-Brion D, Gendrel D, Bozzola M, Chaussain JL \& Job JC. Diagnosis of Kallmann's syndrome in early infancy. Acta Paediatrica Scandinavica $198271937-940$.

16 Dode C, Levilliers J, Dupont JM, De Paepe A, Le Du N, Soussi-Yanicostas N, Coimbra RS, Delmaghani S, Compain-Nouaille S, Baverel F, Pecheux C, Le Tessier D, Cruaud C, Delpech M, Speleman F, Vermeulen S, Amalfitano A, Bachelot Y, Bouchard P, Cabrol S, Carel JC, Delemarre-van de Waal H, Goulet-Salmon B, Kottler ML, Richard O, Sanchez-Franco F, Saura R, Young J, Petit C \& Hardelin JP. Loss-of-function mutations in FGFR1 cause autosomal dominant Kallmann syndrome. Nature Genetics 2003 33 463-465.

17 Legouis R, Hardelin JP, Levilliers J, Claverie JM, Compain S, Wunderle V et al. The candidate gene for the X-linked Kallmann syndrome encodes a protein related to adhesion molecules. Cell $199167423-435$.

Received 28 May 2004

Accepted 8 August 2004 